\title{
Agôn
}

Revue des arts de la scène

Critiques | Saison 2013-2014

\section{Focus sur les Rencontres Chorégraphiques de Seine Saint Denis}

Spectacles de Kat Valástur, Simone Aughterlony et El Conde de Torrefiel

Marion Siéfert

\section{CpenEdition}

Journals

Édition électronique

URL : http://journals.openedition.org/agon/3066

DOI : 10.4000/agon.3066

ISSN : 1961-8581

Éditeur

Association Agôn

Référence électronique

Marion Siéfert, « Focus sur les Rencontres Chorégraphiques de Seine Saint Denis », Agôn [En ligne],

Critiques, mis en ligne le 20 juin 2014, consulté le 23 septembre 2020. URL : http://

journals.openedition.org/agon/3066; DOI : https://doi.org/10.4000/agon.3066

Ce document a été généré automatiquement le 23 septembre 2020.

Association Agôn et les auteurs des articles 


\section{Focus sur les Rencontres Chorégraphiques de Seine Saint Denis}

Spectacles de Kat Valástur, Simone Aughterlony et El Conde de Torrefiel Marion Siéfert

\section{RÉFÉRENCE}

Rencontres chorégraphiques de Seine-Saint-Denis, du 6 mai au 14 juin

Kat Valástur, Oh! Deep Sea - Corpus III (Your whole life passes before your eyes)

Simone Aughterlony, After Life

El Conde de Torrefiel, Escenas para una conversación después del visionado de una película de Michael Haneke.

Renseignements : http://www.rencontreschoregraphiques.com/

\section{NOTE DE L'AUTEUR}

Article également publié sur le site critique Au Poulailler : http://

www.aupoulailler.com/

1 «Dansez, dansez. de toute façon, nous sommes déjà perdus. » Tel semble être le constat des quatre spectacles, découverts lors de cette édition des Rencontres chorégraphiques internationales de Seine-Saint-Denis : la danse ne porte plus l'espoir d'un salut, mais prend acte d'un désespoir qui semble habiter le monde dans lequel nous vivons. Loin d'être l'expression d'une pensée qui résiste, elle devient le lieu transitoire d'une conscience qui s'oublie, s'ennuie et cherche dans les assourdissements des beats et des tubes une manière comme une autre de tuer le temps. Oh! Deep Sea (Kat Valástur), After Life (Simone Aughterlony) et Escenas para una conversación después del visionado de una película de Michael Haneke (El Conde de Torrefiel) tentent, chacun à leur manière, de 
chorégraphier les états d'âme et de trouver le rythme des atermoiements de nos formes de vie occidentales.

\section{Oh! Deep Sea - Corpus III (Your whole life passes before your eyes), Kat Valástur}

Oh! Deep Sea impressionne: cette pièce s'imprime sur la surface rétinienne des spectateurs avec une insistance propre aux choses que l'on connaît déjà, que l'on aurait déjà vécues, mais que l'on reconnaît ici, sur un plateau qui semble plus régi par le rêve ou le cauchemar que par une appréhension réaliste du quotidien. Oh! Deep Sea parle directement à nos consciences. Comme l'indique son sous-titre ("Your whole life passes before your eyes »), ce spectacle en épouse les mémoires.

Oh! Deep Sea - Corpus III (Your whole life passes before your eyes), de Kat Valástur

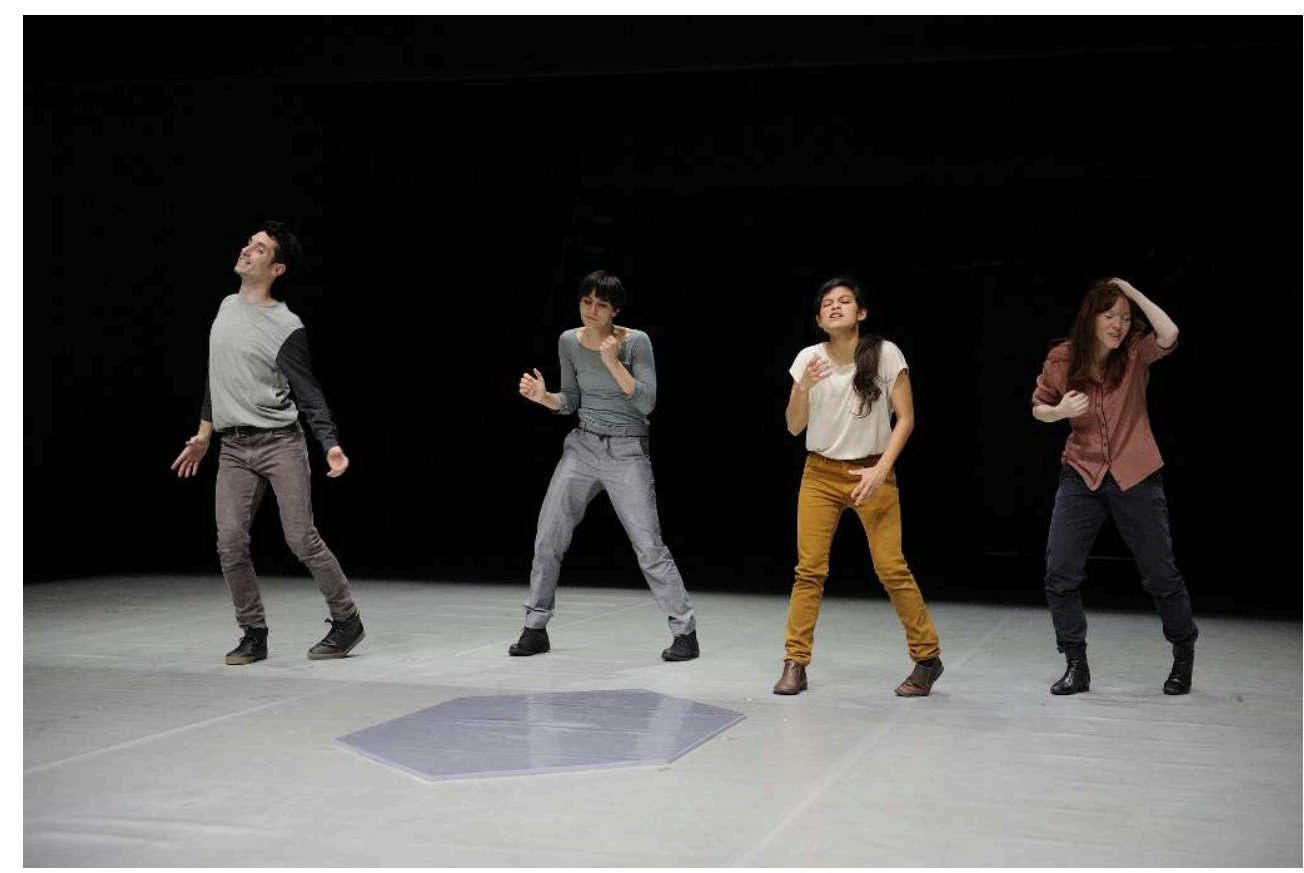

(c) Dieter Hartwig

Le travail de Kat Valástur (Katerina Papageorgiou de son vrai nom) traite le mouvement de manière radicale : il le ralentit. Sur le plateau, quatre danseurs vivent en saccades, comme s'ils étaient éclairés en permanence par des lumières stroboscopiques ou comme s'ils avaient perdu la faculté de se mouvoir avec fluidité, ayant absorbé le rythme heurté et enregistré d'un ralenti vidéo. Le plafond est bas. Au centre de la scène - ici un carré de lumière délimité comme un terrain de jeu - est posée une dalle, point d'attraction mystérieux. Un texte apparaît par moments, audessus, et suggère une narration composée de références picturales, de levers du soleil, de catastrophe, d'incendie. Des personnages apparaissent soudainement, puis s'effacent. Oh! Deep Sea suscite un sentiment de tragique. Le vécu y semble inexorable, comme si l'on était contraint de le revivre une deuxième fois, à l'identique, mais au ralenti. 
Chorégraphe grecque, Kat Valástur va puiser dans une des sources matricielles de la culture occidentale, L'Odyssée, pour en faire ressurgir ce qu'elle appelle les «forces cachées ». Dans cet opus qui s'intéresse au passage d'Ulysse au Royaume des Morts, c'est pourtant notre présent et ses images qui nous sautent aux yeux. Visages oscillant entre le rire et la douleur, danses disloquées et jouissances compulsives, le monde de Oh! Deep Sea est comme déjà mort. Que deviennent nos vies à travers leurs représentations (essentiellement numériques) ? Quelles formes prennent-elles? Quelle influence nos images exercent-elles sur nos existences? Autant d'interrogations qui habitent le spectacle, dans lequel une présence se transforme en absence, une expression de bonheur vire au désespoir. La distorsion que Kat Valástur fait subir au temps (et aux mouvements des danseurs) ne cesse de montrer une action entravée, une impuissance qui semble être devenue le lot des êtres humains, dans un cauchemar où ils se trouveraient prisonniers de leurs propres images.

5 Si fatalité il y a, elle serait à trouver ici : dans l'expérience hachée que nous faisons des choses. Comme si nous ne pouvions nous donner le temps d'être libres.

\section{Simone Aughterlony - After Life}

6 On pourrait dire que le duo conçu par Simone Aughterlony parle d'ajustement et d'accointances. Accointances de la vie et de la mort. Ajustement de deux marginaux, un squelette et un fantôme (Simone Aughterlony et le performer et DJ Nic Lloyd), dans les temps morts que veut bien leur laisser le monde du spectacle dominant. Située dans les coulisses de Show and Tell, précédente pièce de la chorégraphe néo-zélandaise, After Life est un spectacle de l'à-côté, pollué par le flux de discours et de musiques ambiants.

7 Les protagonistes d'After Life sont désœuvrés. Un technicien du théâtre tapote sur son Iphone en attendant que le spectacle situé de l'autre côté de la cloison soit terminé. Applaudissements. Un squelette s'ennuie et tue le temps en cherchant des coins de mur contre lesquels se masturber; cependant qu'un fantôme essaie de libérer son drap coincé dans une porte. Ils écoutent la radio qui, à coups de pubs, de discussions pseudophilosophiques et de musiques entraînantes, célèbre l'expérience, la fête et le divertissement. Dans ce paysage marchand, dans lequel la mort semble ne plus exister, les zombies et autres revenants sont rendus inoffensifs. Devenus eux-mêmes des figures de la grande fête de la mondialisation, Halloween, ils ont perdu toute fonction sociale et testent de nouveaux ajustements corporels, comme lorsque dans un geste régressif, le squelette essaie de rentrer dans le corps du fantôme. Dans After Life, la danse devient une manière comme une autre de secouer un temps trop long, qui n'est plus orienté vers quelque chose, de combler vainement un vide, en attendant que d'autres démontent le décor. "Après la vie, il y a l'ennui ", nous suggère la pièce.

8 C'est qu'After Life est aussi un spectacle poseur qui, paradoxalement, puise son esthétique dans un esprit du temps, où les tee-shirts avec des têtes de mort sont à la mode, où les corps mutants et les spectres font fureur dans le monde de la danse, où le rose et les tubes disco sont le signe d'une société " postmoderne ». After Life se réfugie dans des recettes acceptées par une certaine danse contemporaine: pot-pourri de références populaires et artistiques, une danse qui cite plus qu'elle n'invente, une prééminence d'un discours pseudo théorique qui tend à cloisonner la réception que l'on peut se faire du spectacle. Faute de renouveler son langage, le propos de Simone Aughterlony perd en force et se prive de toute radicalité et insolence. 


\section{El Conde de Torrefiel - Escenas para una conversación después del visionado de una película de Michael Haneke}

9 Scènes pour une conversation après le visionnage d'un film de Michael Haneke (de son nom français) est un spectacle sur la société telle qu'elle est dépeinte en effet dans les films du réalisateur autrichien Michael Haneke: matérialiste, souterrainement violente, perverse. Une société espagnole religieuse, totalitaire et conservatrice qu'entendent dénoncer les membres de la compagnie El Conde de Torrefiel, basée à Barcelone. Interprétées par les cinq performers avec distance et minimalisme, les douze scènes qui composent le spectacle forment une satire des classes moyennes urbaines.

El Conde de Torrefiel - Escenas para una conversación después del visionado de una película de Michael Haneke

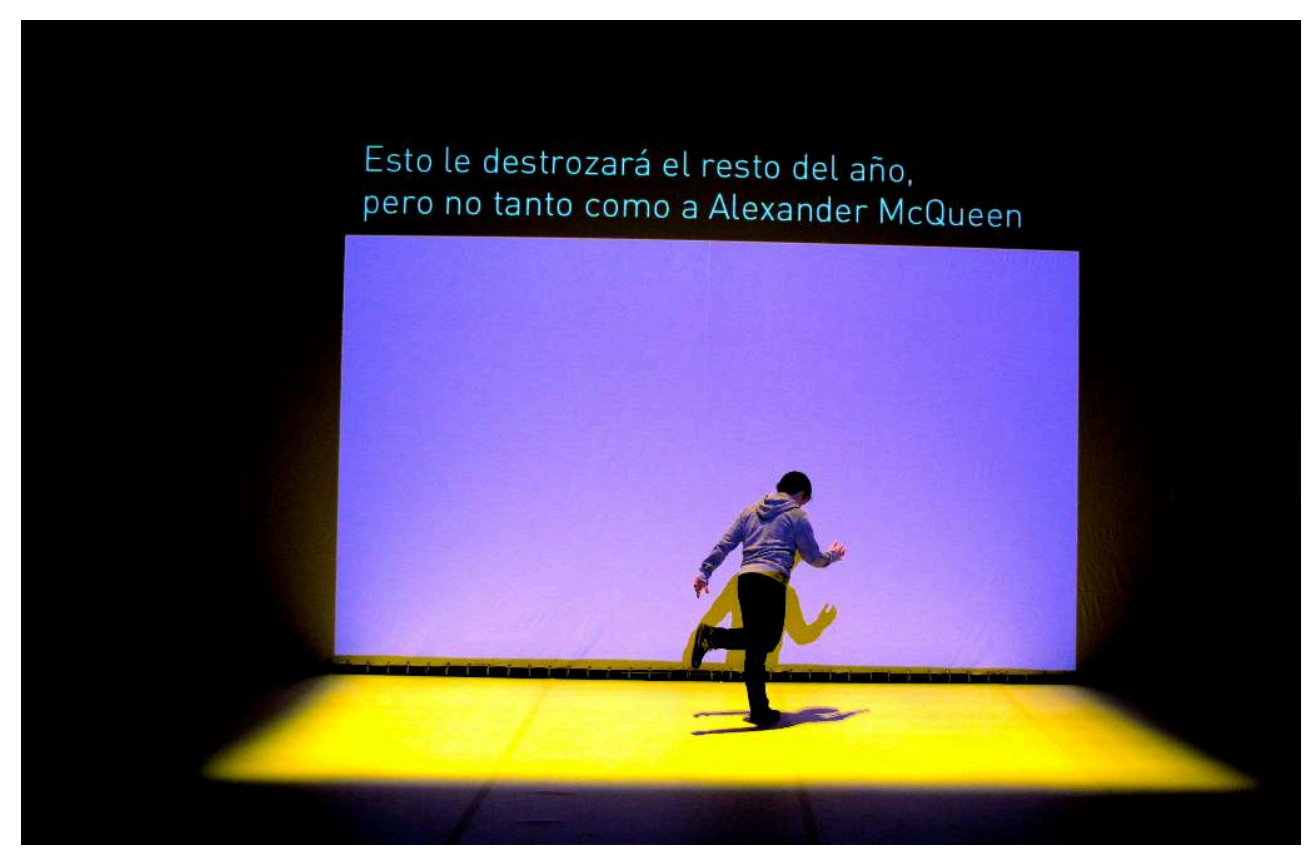

(c) Marcela Prado

10 Alternance monotone entre un récit raconté au micro, dos au public et des surtitres qui illustrent les scènes, les histoires parlent de jeunes personnes prises dans les contradictions de leurs désirs et de leurs modes de vie. Ainsi, un homme vit dans le secret ses fantasmes homosexuels, tandis que sa femme épie les voisins, un jeune homme essaye de s'oublier dans une discothèque pendant que sa mère meurt et des étudiants des Beaux-Arts essaient de soigner leur cynisme dans l'art contemporain. Les fondateurs de la compagnie eux-mêmes apparaissent comme des victimes collatérales du diktat des règles sociales.

11 C'est bien la révolte qui sommeille dans Scènes pour une conversation après le visionnage d'un film de Michael Haneke. Mais elle s'exprime essentiellement sur le ton d'une provocation triste, qui se retourne contre ceux qui la portent. Ne parvenant pas à transformer leur dégoût en autre chose que du mépris, El Conde del Torrefiel se réfugie dans l'écriture de saynètes illustratives. À l'image du tableau initial - un pénis peinant à se redresser - ils semblent déjà découragés. La vision politique qu'ils entendent porter 
souffre de cet engagement plaintif, qui cherche dans des trajectoires personnelles et fictionnelles la preuve de ce qu'ils veulent dénoncer. À force de revendiquer un réalisme plat, El Conde del Torrefiel se prive des armes du militantisme qui, dans le meilleur des cas, n'hésite pas à décoller du réel pour le réinventer. 